\title{
Correlates and Predictive Factors for Alcohol and Other Psychoactive Substance Use among Tanker Drivers in Ilorin, Nigeria
}

\section{Makanjuola Alfred Bamiso* and Buhari Olubunmi Naimat}

Department of Behavioral Sciences, University of Ilorin Teaching Hospital, Ilorin-Nigeria

*Corresponding author: Alfred B Makanjuola, Department of Behavioural Sciences, University of Ilorin Teaching Hospital, Ilorin-Nigeria, Tel: 2348034990495; E-mail: makanju2@yahoo.com

Received date: May 18, 2014, Accepted date: June 9, 2014, published date: June 17, 2014

Copyright: (C) 2014 Alfred B Makanjuola, et al. This is an open-access article distributed under the terms of the Creative Commons Attribution License, which permits unrestricted use, distribution, and reproduction in any medium, provided the original author and source are credited.

\begin{abstract}
Objectives: To determine the prevalence, correlates and predictive factors associated with use of commercial and non-commercial alcohol and other psychoactive substances among tanker drivers in Ilorin, Nigeria

Method: A cross sectional weighted proportionate simple random sampling of TDs was selected for the study. Respondents who gave consent to partake in the study and satisfy the inclusion criteria were interviewed using the modified version of the WHO student drug survey questionnaire.

Results: Among the 400 respondents, there was a relatively high level of information and knowledge concerning the presence, availability and use of alcohol, tobacco, caffeine and cannabis. Lifetime use prevalence for alcohol use was $49.8 \%$, tobacco $67.8 \%$, caffeine $66.8 \%$ and cannabis $37.3 \%$ while the current use prevalence of alcohol was $31 \%$. Predictive factors for current drug use were presence of multiple sex partners and previous involvement in road traffic accidents. Accident rate was significantly higher among current alcohol users $(43.8 \%)$ and current cannabis users $(53.7 \%)$. Lifetime cannabis, alcohol and caffeine use were predictive of previous road traffic accident.
\end{abstract}

Conclusion: Efforts should be intensified towards increased and sustained education programmers on alcohol and other drugs, not just among TDs but the entire populace.

\section{Keywords:}

Predictive factors; Tanker drivers; Alcohol and other drugs; Nigeria

\section{Introduction}

In Nigeria, the major means of distributing petroleum products is by road. Previous reports have suggested an association between psychoactive substance use and accidental injury or death. For example, alcohol is thought to contribute to 50,000 deaths per year and up to 500,000 hospital admissions annually in the United Kingdom [1]. Alcohol use and being young has been referred to as a 'deadly mix' causing about 10,000 deaths in the United States of America [2]. In Nigeria, the WHO has reported a link between drivers' hazardous use of alcohol and road traffic accidents [3]. Approximately 50\% of accidents, and its attendant consequences, on Nigerian roads have been shown to be related to alcohol use [4]. Other studies in Nigeria have also reported common use of alcohol (and other psychoactive substances) among commercial and long distance vehicle drivers $[5,6]$. Omolase et al reported a prevalence of $32 \%$ of alcohol drinking prior to driving [7]. The Global action on Harmful drinking reported the prevalence of current drinking by commercial drivers in Nigeria (from Port Harcourt and Ile-Ife) as $67.2 \%$. Of these, $47 \%$ were "heavy" users, $15.3 \%$ were "moderate" users and $37.7 \%$ were occasional or "mild" users. In addition, between $60 \%$ and $70 \%$ of commercial drivers engage in drinking and driving [8]. It has also been reported that driving was done with concomitant use of the following psychoactive drugs: alcohol (15.9\%), tobacco (30.4\%), cannabis (4.3\%), caffeine (31.9\%), sedatives (10.1\%) and solvents (8.7\%) [5].

In spite of the above, the use of psychoactive substances and driving has continued unabated in Nigeria. The Federal Road Safety Corp and other civil organizations have continued to put up campaigns against drunk-driving. Unfortunately, the enforcement aspect against drunkdriving has been unsuccessful as there is no legal definition of the upper limit of blood alcohol concentration (BAC) in the Nigerian Traffic laws [4].

In spite of the known serious consequences associated with the use of alcohol and psychoactive drugs among automobile drivers (such as road traffic accidents, loss of body parts and injuries), there is a need to address other sequalae that are equally detrimental to the development of the society. These will include the known association between increased high risk sexual behavior and psychoactive substance use $[6,9,10]$ and disruption of social networks due to disturbed behavior and strained social and occupational relationships $[11,12]$ Other consequences include hepatitis B, C, carcinoma of the lungs, liver cirrhosis and primary liver carcinoma, alcohol hallucinosis and dementia. It is also important to remember the economic consequences that often result from accidents such as damage to properties and infrastructures.

In Nigeria, it is not uncommon for non-commercial alcohol to be sold in or around the motor parks. They are sold as herbal concoctions against malaria or low back aches popularly referred to as jedi-jedi. Often the buyers are unaware of the components of such herbal drugs 
especially the alcohol content. Though there have been studies on prevalence, pattern and psychosocial correlates of alcohol and other psychoactive substance use among various groups and subgroups in Nigeria [13-16] including long distance vehicle drivers [5], there are no existing published studies on drug use among this important group of petroleum tanker drivers. This study, therefore, is aimed at one, determining the prevalence of alcohol and other psychoactive substance use among petroleum tanker drivers in Ilorin and two determine psychosocial factors correlates and predictive factors that are associated with substance use among the respondents.

\section{Method}

\section{The study setting}

Ilorin is a gateway city which is located almost halfway between the northern and southern part of Nigeria. It has a population of about 2.5million [18] and a fuel depot located in its outskirts at Oke-Oyi. In addition, there are articulated vehicle parks at Olooru and Gbede, both in the outskirts of the town. Most articulated vehicles and petroleum tankers usually make a stop-over in Ilorin or its outskirts to refill fuel, eat, drink or rest. It is therefore a good location to interview the TDs. The total number of tanker drivers (registered or not, or in-transit), as estimated by the organized tanker drivers union was about 4000 .

\section{Sample size determination}

Using the Fisher's formula [19] and allowing for a $10 \%$ attrition rate, a calculated sample size of 393 (rounded up to 400) was obtained. However, since the estimated population of TDs in Ilorin was about 4000 , a proportionate sampling of $10 \%$ [20] of TDs was 400. In Ilorin, Oke-Oyi depot has the largest concentration (50\%) of TDs while Gbede and Olooru each have about $25 \%$ of TDs each. Consequently, 200 TDs were sampled in Oke-Oyi depot, 100 TDs from Gbede and 100 TDs from Olooru.

\section{Instrument for data collection}

This consists of a modified, semi-structured self-report questionnaire based on the World Health Organization's guidelines for student substance use survey [20]. This instrument have been previously used among students in Nigeria and found reliable and valid $[11,13,21,22]$. The modified version of the questionnaire, has also been previously used among long distance vehicle drivers in Ilorin, Nigeria [5]. The modified questionnaire consists of items that sought information on the respondents' socio-demographic characteristics, frequency of use of substances, types of substances used (alcohol e.g beer, palm wine; caffeine e.g kola acuminata; amphetamine; cocaine; opioids; solvents), respondents' frequency of involvement in road traffic accidents, attendance at health talks on drug abuse, and suggested methods of curbing substance use, among other items.

\section{Ethical considerations}

Ethics approval for the study was obtained from the Ethics Committee of the University of Ilorin Teaching Hospital Ilorin (NHREC/02/05/2010). All the participants were duly informed about the study and its purpose. Informed consent was also obtained from them. Participants were reassured of utmost confidentiality of information given by them.

\section{Inclusion criteria}

All petroleum tanker drivers (having a designated route of 5 hours drive, with or without a stop-over) seen at the motor parks within the study period and gave consent to participate in the study. The respondents must have attained the minimum legal driving age of 18 years. In Nigeria, though there is no minimum legal drinking age, there are social restrictions against drinking by those aged less than 18 years

\section{Procedure}

A pilot study was conducted among 20 randomly selected nonpetroleum tanker drivers in Young Legacy Park in Ilorin. The questionnaire items were well understood and could be complete within 20 minutes on the average. During the main study, a simple random sampling of a weighted proportionate sample of all petroleum tanker drivers who satisfy the inclusion criteria and consent to participate in the study was done. Respondents were reassured of confidentiality of information given.

\section{Data analysis}

Data was analyzed using the SPSS version 17 software. Frequency tables and means were generated and relevant cross tabulations done. Proportions were compared using chi-square test while means were compared using F statistics/ t-test. Univariate and multivariate regression analysis were done to determine factors that were associated and predictive for substance use.

\section{Results}

Of 430 respondents targeted, 22 did not meet the inclusion criteria, 5 out rightly refused to participate in the study while 3 did not complete the interview. The total completed interview was 400 . The reasons given for refusal to participate was fear of the information being used against them while the non completion of interview were due to, according to the respondents, asking 'irritating' questions such as 'how many children do you have' and 'do you have sexual partners'.

\section{Sociodemographic characteristics of respondents}

Completed interview was collected from 400 tanker drivers comprising of 200 from Oke-Oyi Nigerian National Petroleum Corporation (NNPC) depot park, 100 from Olooru motor Park and 100 from Gbede Motor Park. All of them were males and aged 20-70 years with a mean of $42.2 \pm 10.9$ years. Majority $(77.5 \%)$ claimed they were very religious, $17 \%$ claimed they were moderately religious while $5.5 \%$ were not religious. A half (50\%) of them had primary school education, $26.8 \%$ had secondary school education, $2 \%$ had tertiary education, while $20.3 \%$ had no formal education. The years of driving experience of the tanker drivers ranged from 1-55 years with a mean of $15.7 \pm 10.3$ years. About a third of them (35.5\%) earned above N10,000 (USD64.00) per week, while the remaining earned less than $\$ 64 /$ week. For those who are married, almost all had a relatively stable relationship with their spouse. One hundred and forty nine (37.3\%) had sex partners which ranged from 1-16 with most claiming to have one or two partners. About $95 \%$ of the respondents had cordial relationship with their employers while 393 (98.2\%) claimed they had perceived occasional or no emotional problems. 


\section{d other psychoactive substances}

A significant majority of the respondents have heard, seen or know someone who used alcohol, tobacco, cannabis and caffeine. The level of knowledge concerning other substances was relatively low with knowledge on steroids being the least. Peers introduced $60.3 \%$ of respondents to drug use. The reasons given for using drugs, in descending order, were pleasure $(32.8 \%)$, to be alert while driving $(27.3 \%)$; to relief tension (8\%), imitation of others $(6.8 \%)$ and no specific reason (2.5\%). Majority (77\%) were aware of the consequences of alcohol and other psychoactive substance use. Two hundred and forty four $(61 \%)$ claimed the use of alcohol and other psychoactive substances is a menace that is on the increase among drivers, while 120 (30\%) said it is decreasing. The preferred methods of addressing the issue of substance abuse were; referral to a doctor/hospital $18 \%$, referral to a counselor $81.5 \%$, frequent health campaigns (39\%) and punitive measures by law enforcement agents (39\%).

Though $83 \%$ have heard of anti drug campaigns, only $51 \%$ had actually attended one. One hundred and forty five (36.3\%) of the respondents have had previous road traffic accidents. Only 51 (12.8\%) of this claimed it was due to influence of alcohol and other psychoactive substances. The drugs mentioned as being responsible were cannabis $(43.1 \%)$, alcohol (23.6\%), caffeine (19.6\%), and tobacco (3.9\%). Eighty three $(20.8 \%)$ of the respondents keep psychoactive drugs in their vehicles, while 164 (41\%) use alcohol and other psychoactive drugs when they stop over. The drugs used at stop over points include alcohol (34.8\%), caffeine (22.6\%), cannabis $(20.7 \%)$ and tobacco (18.9\%).

\section{Prevalence of use of alcohol and other psychoactive substances}

The lifetime use prevalence of psychoactive substances was; caffeine (66.8\%), tobacco $(67.8 \%)$, alcohol $(49.8 \%)$, cannabis $(37.3 \%)$, sedatives (13.5\%) and amphetamines (11.5\%). The current use prevalence was; caffeine $(61.5 \%)$, tobacco $(53.3 \%)$, alcohol $(31 \%)$, sedatives $(10.8 \%)$ and amphetamines (4.8\%). The current use pattern shows daily use of tobacco as $51.8 \%$, caffeine $47.5 \%$, alcohol $17.3 \%$ and cannabis $13.8 \%$. Twenty six $(6.5 \%)$ claimed they will still use tobacco in future while $3.5 \%$ claimed they will use alcohol in future (Table 1).

\begin{tabular}{|c|c|c|c|c|c|c|}
\hline Substance & Previous Total & & $\begin{array}{l}\text { Current use pattern } \\
(\%)\end{array}$ & & & lifetime \\
\hline & use & Current \% & Occasional & often use & daily & use $(\%)$ \\
\hline Tobacco & $57(14.3)$ & $214(53.5)$ & $5(1.3)$ & $2(0.5)$ & $207(51.8)$ & $271(67.8)$ \\
\hline Alcohol & 75 (18.8) & $124(31)$ & $35(8.8)$ & $20(5)$ & $69(17.3)$ & $199(49.8)$ \\
\hline Cannabis & 59 (14.8) & $90(22.5)$ & $21(5.3)$ & $14(3.5$ & $190(47.5)$ & $149(37.3)$ \\
\hline Caffeine & $25(6.3)$ & $246(61.5)$ & $37(9.3)$ & $19(4.8)$ & $190(47.5)$ & $271(66.8)$ \\
\hline Strong stimulant & $27(6.8)$ & $19(4.8)$ & $2(0.5)$ & $1(0.3)$ & $16(4)$ & $46(11.5)$ \\
\hline Sedative & $11(2.8)$ & $43(10.8)$ & $19(4.8)$ & $20(5)$ & $4(1)$ & $54(13.5)$ \\
\hline Steroid & $3(0.8)$ & $58(14.5)$ & $13(3.3)$ & $43(10.8)$ & $2(0.5)$ & $61(15.3)$ \\
\hline Cocaine & $1(0.3)$ & $2(0.5)$ & $1(0.3)$ & $1(0.3)$ & $0(0)$ & $3(0.8)$ \\
\hline Heroin & $3(0.8)$ & $27(6.8)$ & $8(2)$ & $18(4.5)$ & $1(0.3)$ & $30(7.6)$ \\
\hline Solvents & $8(2)$ & $17(4.3)$ & $4(1)$ & $10(2.5)$ & $3(0.8)$ & $25(6.3)$ \\
\hline
\end{tabular}

Table1: Prevalence rates of Alcohol and other psychoactive substance use among Tanker drivers (TDs) in Ilorin (N=400) Percentages may add up to more than $100 \%$ because of multiple responses (polysubstance use).

\section{Vehicular accident rate and alcohol and other substance use:}

The rate of vehicular accidents among alcohol users was $43.8 \%$ while the rate in non-alcohol users was 33\% (Pearson $\chi^{2}=4.3 ; \mathrm{p}=0.04$ ). The accident rate among cannabis users was $57.3 \%$. Also, $27.3 \%$ of current users of alcohol were cannabis users while $37.1 \%$ of current cannabis users were current users of alcohol (Pearson $\chi^{2}=2.5 ; \mathrm{p}=0.11$ ).

\section{Psychosocial factors associated with total current use of alcohol and other psychoactive substances}

Logistic Regression analysis: A univariate binary or multinomial regression analysis of level of religiosity, age, level of education, income, driving experience, number of children, presence of sex partner, perceived level of physical wellness, perceived level of emotional wellness, having had previous road traffic accident, and having heard of antidrug abuse campaign was done using current use of alcohol, tobacco, cannabis and alcohol containing concoctions as dependent variables.

Tables 2, 3 and 4 show that age, level of income, driving experience, presence of sex partners, perceived emotional wellness and previous road accident were found to have significant association with current use of alcohol. However, multivariate regression analysis of all the significant factors showed that only income $(\mathrm{p}=0.04 ; \mathrm{OR}=0.460$; $95 \% \mathrm{CI}=0.249-0.851)$ and presence of sex partners ( $\mathrm{p}=0.000$; $\mathrm{OR}=0.187 ; 95 \% \mathrm{CI}=0.114-0.306$ ) were found to be significant. Both univariate and multivariate regression showed that level of education $(\mathrm{p}=0.02 ; \mathrm{OR}=7.69 ; 95 \% \mathrm{CI}=1.378-42.93)$, presence of sex partners (0.001; OR $=0.464 ; 95 \% \mathrm{CI}=0.299-0.719)$ and previous road traffic accident $(\mathrm{p}=0.001 ; \mathrm{OR}=0.488 ; 95 \% \mathrm{CI}=0.317-0.751)$ had predictive values for current use of tobacco. For current use of cannabis, 
Citation: Bamiso MA, Naimat BO (2014) Correlates and Predictive Factors for Alcohol and Other Psychoactive Substance Use among Tanker Drivers in llorin, Nigeria. J Psychiatry 17: 132. doi:10.4172/2378-5756.1000132

Page 4 of 7

univariate regression analysis shows that level of religiosity $(\mathrm{p}=0.004)$, presence of sex partners $(\mathrm{p}=0.007)$ and previous road traffic accident $(\mathrm{p}=0.000)$ were significant. On multivariate regression analysis, only level of religiosity $(\mathrm{p}=0.007 ; \mathrm{OR}=4.518 ; 95 \% \mathrm{CI}=1.516-13.462)$ and previous accident $(\mathrm{p}=0.000 ; \mathrm{OR}=0.300 ; 95 \% \mathrm{CI}=0.178-0.505)$ were found to be predictive.

Presence of sex partners $(\mathrm{p}=0.000 ; \mathrm{OR}=0.326 ; 95 \% \mathrm{CI}=0.195-0.544)$ was found to be predictive of current use of alcohol containing concoctions. Among respondents who currently use both alcohol and cannabis, presence of sex partners $(\mathrm{p}=0.000 ; \mathrm{OR}=0.109$; $95 \% \mathrm{CI}=0.043-0.272)$ and previous accident $(\mathrm{p}=0.010 ; \mathrm{OR}=0.372$;
$95 \% \mathrm{CI}=0.175-0.791)$ were found to have significant association. On multivariate analysis, both factors were also found to be predictive.

Previous road traffic accident was significantly associated with lifetime use of alcohol, tobacco, cannabis, caffeine and amphetamine. Presence of sex partners was found (after adjusting for confounding variables) to be significantly predictive for the use of alcohol, tobacco, cannabis, caffeine, amphetamines and alcohol containing concoctions. Lifetime cannabis use was predictive (after adjusting for confounding variables $)$ of previous accident $(\mathrm{p}=0.005 ; \mathrm{OR}=01.986 ; 95 \% \mathrm{CI}=$ 1.229-3.202).

\begin{tabular}{|c|c|c|c|c|c|c|c|c|}
\hline $\begin{array}{l}\text { Current alcohol } \\
\text { use }\end{array}$ & & & & & $\begin{array}{l}\text { current } \\
\text { tobacco use }\end{array}$ & & & \\
\hline \multicolumn{9}{|l|}{$\begin{array}{l}\text { current cannabis } \\
\text { use }\end{array}$} \\
\hline & $\mathrm{p}$ & b & OR & $95 \% \mathrm{Cl}$ & $\mathrm{p}$ & b & OR & $95 \% \mathrm{Cl}$ \\
\hline & b & OR & $95 \% \mathrm{Cl}$ & & & & & \\
\hline \multirow[t]{2}{*}{ Age } & 0.01 & -0.026 & 0.975 & $0.96-0.99$ & 0.538 & -0.006 & 0.994 & $0.98-1.012$ \\
\hline & 0.391 & 0.010 & 1.010 & $0.99-1.032$ & & & & \\
\hline \multirow[t]{2}{*}{ Level of relg } & 0.091 & 1.025 & 2.79 & $0.85-9.15$ & 0.689 & -0.203 & 0.816 & $0.302-2.215$ \\
\hline & 0.004 & -1.500 & 0.223 & $0.080-0.626$ & & & & \\
\hline \multirow[t]{2}{*}{ Education } & 0.058 & 0.18 & 1.19 & $0.63-2.29$ & 0.02 & 0.70 & 2.018 & $1.1-3.6$ \\
\hline & 0.909 & -0.042 & 0.96 & $0.47-1.96$ & & & & \\
\hline \multirow[t]{2}{*}{ Income } & 0.007 & +0.687 & 2.074 & $1.2-3.5$ & 0.26 & -0.284 & 0.753 & $0.458-1.236$ \\
\hline & 0.259 & -0.328 & 0.721 & $0.408-1.272$ & & & & \\
\hline \multirow[t]{2}{*}{ Driving expe } & 0.005 & -0.029 & 0.97 & $0.95-0.99$ & 0.738 & 0.003 & 1.003 & $0.984-1.023$ \\
\hline & 0.143 & 0.018 & 1.018 & $0.994-1.067$ & & & & \\
\hline \multirow[t]{2}{*}{ No children } & 0.384 & 0.026 & 1.026 & $0.97-1.09$ & 0.450 & -0.021 & 0.536 & $0.4-0.8$ \\
\hline & 0.987 & 0.001 & 1.000 & $0.938-1.067$ & & & & \\
\hline \multirow[t]{2}{*}{ Sex partners } & 0.000 & -1.561 & 0.210 & $0.13-0.3 \quad 0.003$ & -0.620 & 0.536 & $0.4-0.8$ & 0.007 \\
\hline & 0.651 & 0.52 & $0.3-0.8$ & & & & & \\
\hline \multirow[t]{2}{*}{ Emotional wel } & 0.925 & 0.025 & 1.025 & $0.61-1.73$ & 0.100 & 0.414 & 1.513 & $0.924-2.48$ \\
\hline & 0.811 & -0.071 & 0.931 & $0.519-1.672$ & & & & \\
\hline \multirow[t]{2}{*}{ Prev accident } & 0.039 & -0.460 & 0.63 & $0.4-1.0$ & 0.000 & -0.729 & 0.482 & $0.3-0.7$ \\
\hline & 0.000 & -1.131 & 0.323 & $0.2-0.5$ & & & & \\
\hline \multirow[t]{2}{*}{ Heard campa } & 0.236 & 0.330 & 1.391 & $0.81-2.40$ & 0.773 & 0.077 & 1.080 & $0.64-1.82$ \\
\hline & 0.169 & -0.486 & 0.615 & $0.308-1.230$ & & & & \\
\hline
\end{tabular}

Table 2: Univariate binary/multinomial logistic regression among TDs in Ilorin N.B: Level of relg= level of religiosity; Driving expe= driving experience; Emotional wel $=$ emotional wellness; Prev accident $=$ previous accident; Heard campa $=$ heard of campaign.

\section{Non commercial alcohol use among tanker drivers}

About $48 \%$ claimed they drink locally made concoctions while at work or just before coming to the motor park. Seventy six (19\%) claimed they were aware that the concoctions contain alcohol, while
$81 \%$ said the concoctions do not contain alcohol. Of the 190 drivers who take concoctions, $16.3 \%$ of them still take commercial alcohol in addition. The most frequently used alcohol containing concoctions include jedi $(52.3 \%)$, agbo iba $(30.3 \%)$, opa eyin (28\%), ale (20\%). The 
Citation: Bamiso MA, Naimat BO (2014) Correlates and Predictive Factors for Alcohol and Other Psychoactive Substance Use among Tanker Drivers in llorin, Nigeria. J Psychiatry 17: 132. doi:10.4172/2378-5756.1000132

Page 5 of 7

mean daily consumption of these alcohol containing concoctions ranged from $50-300 \mathrm{mls}$ with a mean of $80 \pm 67.6 \mathrm{mls}$. The concoctions are usually made from roots and barks of medicinal plant soaked in $125-250 \mathrm{mls}$ of commercial (43\% alcohol volume) alcohol diluted with about $300 \mathrm{mls}$ of water. However, few concoctions were said to be diluted with non-alcohol beverages (which may undergo fermentation with time) or water only.

\begin{tabular}{|c|c|c|c|c|c|c|c|c|}
\hline $\begin{array}{l}\text { cannabis/alcohol } \\
\text { use }\end{array}$ & $\begin{array}{l}\text { Current concoction } \\
\text { with alcohol use }\end{array}$ & & & & current & & & \\
\hline & $p$ & $\mathrm{~b}$ & OR & $95 \% \mathrm{Cl}$ & $\mathrm{p}$ & $\mathrm{b}$ & OR & $95 \% \mathrm{Cl}$ \\
\hline Age & 0.764 & 0.004 & 1.004 & $0.981-1.027$ & 0.229 & -0.020 & 0.98 & $0.95-1.01$ \\
\hline Level of relg & 0.123 & 1.040 & 2.830 & $\begin{array}{l}0.755-10.61 \\
3\end{array}$ & 0.120 & 0.29 & 1.33 & $0.261-6.805$ \\
\hline Education & 0.229 & 0.485 & 1.624 & $0.737-3.579$ & 0.889 & 0.72 & 1.08 & $0.391-2.959$ \\
\hline Income & 0.232 & 0.380 & 1.462 & $0.784-2.728$ & 0.805 & 0.108 & 1.114 & $0.473-2.625$ \\
\hline Driving expe & 0.827 & 0.003 & 1.003 & $0.978-1.028$ & 0.171 & -0.023 & 0.978 & $0.946-1.010$ \\
\hline No children & 0.407 & 0.030 & 1.030 & $0.960-1.105$ & 0.635 & -0.022 & 0.978 & $0.893-1.072$ \\
\hline Sex partners & 0.000 & -1.122 & 0.326 & $0.2-0.5$ & 0.000 & -2.201 & 0.111 & $0.05-0.28$ \\
\hline Emotional well & 0.538 & 0.187 & 1.206 & $0.605-2.186$ & 0.675 & 0.179 & 1.196 & $0.519-2.757$ \\
\hline Prev accident & 0.150 & -0.373 & 0.688 & $0.414-1.144$ & 0.010 & -0.954 & 0.385 & $0.19-0.79$ \\
\hline Heard campaign & 0.331 & 0.310 & 1.364 & $0.730-2.548$ & 0.882 & -0.070 & 1.072 & $0.425-2.705$ \\
\hline \multicolumn{9}{|l|}{$\begin{array}{l}\text { Multivariate } \\
\text { regression analysis }\end{array}$} \\
\hline \multirow[t]{2}{*}{ Sex partners } & 0.000 & & & & Sex partners & 0.000 & & \\
\hline & & & & & $\begin{array}{l}\text { Previous } \\
\text { accident }\end{array}$ & 0.010 & & \\
\hline
\end{tabular}

Table 3: Univariate binary/multinomial logistic regression among TD in Ilorin.

\begin{tabular}{|l|l|l|l|l|}
\hline Substance & $\mathbf{p}$ & $\mathbf{b}$ & OR & $\mathbf{9 5 \%} \mathbf{C l}$ \\
\hline Tobacco & 0.000 & 0.913 & 2.492 & $1.559-3.984$ \\
\hline Alcohol & 0.011 & 0.536 & 1.709 & $1.133-2.580$ \\
\hline Cannabis & 0.000 & 1.057 & 2.878 & $1.881-4.403$ \\
\hline Caffeine & 0.001 & 0.790 & 2.204 & $1.382-3.515$ \\
\hline Amphetamine & 0.001 & 0.968 & 2.631 & $1.462-4.735$ \\
\hline $\begin{array}{l}\text { Alcohol } \\
\text { containing } \\
\text { Concoction }\end{array}$ & 0.150 & -0.373 & 0.478 & $0.318-0.721$ \\
\hline
\end{tabular}

Table 4: Logistic regression analysis of previous accident against lifetime use of substances among TDs in Ilorin, Multivariate regression of all significant variables shows that previous accident was dependent on Lifetime use of only cannabis $(\mathrm{p}=0.005)$.

\section{Discussion}

The response rate obtained (98.8\%) was higher than the $72.6 \%$ recorded in previous study among long distance vehicle drivers in Ilorin [5]. This might be due to the better collaboration between the researcher and the tanker drivers union officials. They assisted the in identification and initial contact with the respondents. The presence of

the union officials assisted in reassuring the respondents that information obtained will not be used against their interest. It is worthy of note that in both study locations, the commonly used psychoactive substances were tobacco, alcohol, caffeine and cannabis. This is similar to findings in previous studies in Nigeria $[11,13]$.

The mild stimulants used by respondents contain caffeine which is usually taken in form of coffee drink/tea or kola nut (kola acuminata). Most of the respondents (99\%) use kola nut (a caffeine containing nut which is usually chewed). Another variant of kola nut that has mild stimulant effect is Orogbo (garcinia cola) but this was not mentioned by any respondent. The strong stimulants usually used contain amphetamine and are usually taken in form of Kwaya among the youth, drivers, especially long distance vehicle drivers and labourers, particularly those from the northern part of Nigeria.

The influence of peers in introducing respondents to alcohol and other psychoactive substances was most reported (60.3\%). This was closely followed by self induced experimentation. This observation is in keeping with previous findings that have identified peer influence as one of the important predisposing factors to substance use and abuse $[11,17]$. A significant proportion of the respondents have good knowledge about the types of psychoactive substances that are available, are aware of the consequences of its use or abuse, and reported that drug use among drivers constitute a problem which is also on the increase. However, it is worthy of note that only $51 \%$ of 
respondents had ever attended a drug abuse campaign programme. This will suggest a need for more intense drug education programs for the petroleum tanker drivers in Ilorin and possibly other locations in Nigeria. This suggestion is even more pertinent when we consider the fact that the prevalence of current alcohol use among the respondents is $31 \%$.

Almost half of the respondents use psychoactive substances when they stop-over; with alcohol being the most commonly used substance by $34.8 \%$ of the respondents. More efforts should therefore be made to increase education and regulation of substance use at the various motor parks or stop over points in Nigeria.

Though several studies have been done in Nigeria in the area of commercial alcohol use, not many have been reported concerning non-commercial alcohol use. Over $75 \%$ of the world population is currently using herbal products with increasing trend globally. While the herbs may have some beneficiary effects, they are not completely harmless. Previous studies in Lagos showed the prevalence of use of herbal products to be $66.8 \%$.[23,24] with the two most commonly used herbal products being agbo jedi (35\%) and agbo iba (27.5\%) [24] Currently in Nigeria, the use of local herbs is prevalent. The herbal concoctions are usually compounded using herbal plants parts such roots and barks, or leaves of plants such as pawpaw (carica papaya), neem (azadirachta indica) tree or mango (mangifera $\mathrm{sp}$ ) tree. Some of the plants or animal extracts used vary from one community to another. Usually, commercial alcohols are used as the extracting solvent or as preservative. This method is similar to what has been reported in previous studies on herbal medicinal plants in Europe [25]. Sometimes, non-alcoholic beverages, which tend to undergo fermentation over time, are used. In our study, $19 \%$ of the respondents claimed the concoctions they take contain commercial alcohol. In addition to the alcohol containing concoctions, $16.3 \%$ of respondents still take additional commercial alcohol concomitantly. Such use of alcohol containing herbal products in conjunction with commercial alcohol has been reported to cause toxic reactions [25]. The rate of concomitant use of alcohol of $29.9 \%$ previously reported among adolescents using herbal products [26] is comparable to the rate reported in our study. Consequently, it has therefore become imperative for future studies to determine the concentration of psychoactive substances in these herbal products. This will enable stakeholders carry out appropriate education, legislation and enforcement policies.

Our study shows that presence of sexual partners was a predictive factor for current alcohol, tobacco, cannabis, cannabis/alcohol and 'alcohol containing concoctions' use. This relationship was inverse across all the drugs. This might be because current alcohol users tend to socialize more 27, possibly go out more with peers and therefore are more likely to be exposed to other aspects of outdoor social life which most times include friendship and relationship with the opposite sex.

It is also worthy of note that almost half of the TDs currently using alcohol (43.8\%) and 57\% of current users of cannabis have been involved in road traffic accident. This should be of concern especially when such incidents could have been associated with damage to properties, environment, and loss of body parts or even lives. This will further underscore the timeliness of this study and a need to quickly institute intense drug education programmes among the TDs.

Religiosity has been reported to have inverse relationship with substance use [28-30]. However; there are also debates on the influence of religiosity and spirituality on substance abuse [30]. It has been reported that religiosity only have significant inverse relationship with illicit drugs when compared with more permissible social drugs such as alcohol [30]. Our study supports this observation as current alcohol and tobacco use did not have a significant association with level of religiosity. However, current use of cannabis, had a significant association with level of religiosity (Pearson $\chi 2=36.2 ; \mathrm{p}=0.000$ ).

Our current finding of the relationship between religiosity and alcohol use as opposed to previous findings in Nigeria, may be a reflection of a gradual divide between concept of spirituality and religiosity among Nigerians. This might not be unconnected with the explosion of new religious sects whose doctrines tend to differ from those of previously existing orthodox religious bodies. Since religiosity may not necessarily equate with spirituality, we suggest that future studies should test the relationship of substance use with both religiosity and spirituality. This might assist in the development of future models concerning the use of religion, religiosity and spirituality in the management of substance abuse.

\section{Conclusion}

Road transportation using articulated vehicles is the major means of distribution of petroleum products in Nigeria. It was found that previous road traffic accident was significantly associated with lifetime use of alcohol, tobacco and cannabis. There is therefore a need for immediate promulgation of laws, including defined legal limits of alcohol in Nigeria (and in similar countries where this does not exist) against driving under influence. Also, there should be an increased and sustained drug education programmes, not just among petroleum tanker drivers, but the entire citizenry.

\section{Disclosures}

This research was funded by International Centre for Alcohol Policy (ICAP), Brussels Office. However, the proposal, data collection, analysis, interpretation and manuscript preparation were prepared by Makanjuola A.B and Buhari O.I.N. The research, interpretations and all views expressed are those of the authors and NOT necessarily those of the ICAP or its sponsor companies.

\section{Conflict of Interest}

None

\section{References}

1. Humphis T, Bennett M, Ray C (1991) Warning; Alcohol can damage your health. London. Alcohol Concerns.

2. New York Times 27th, May 2013 (also, The Punch Newspapers Thursday, June 27th, 2013, pg 56).

3. World Health Organization (2009) Global status report on road safety: Time for action. Geneva, Switzerland.

4. Welcome MO, Pereverzev VA (2010) Limit of blood alcohol concentration: A major problem to solve in Nigeria. European Psychiatry 25: 544

5. MakanjuolaAB, Oyeleke AS, Akande TM (2007a)Psychoactive substance use among long distance vehicle driver in Ilorin. Nigerian Journal of Psychiatry 5: 14-18.

6. UNAIDS Joint Regional STI/HIV/AIDS Project in the Abidjan-Lagos Transport Corridor. 2007.

7. Omolase CO, Afolabi OT, Omolase BO and Ihemedu CO (2011) Drinkdriving among commercial drivers in a Nigerian community. Middle East Journal of Psychiatry and Alzheimer's 2: 15-19. 
Citation: Bamiso MA, Naimat BO (2014) Correlates and Predictive Factors for Alcohol and Other Psychoactive Substance Use among Tanker Drivers in llorin, Nigeria. J Psychiatry 17: 132. doi:10.4172/2378-5756.1000132

Page 7 of 7

8. Gboyega EA (2012) Psycho-spatial predictors of alcohol use among drivers in Ibadan, Nigeria: Implications for preventing vehicular accidents. International Journal of Alcohol and Drug Research 1: 1-10.

9. Donna HM, Shannon C, Dale S, Sarah V, Nick K, Jaime V, Steven AJ (2010) Sexual and Drug Use Risk Behaviours of Long-Haul Truck Drivers and Their Commercial Sex Contacts in New Mexico. Public Health Rep 125: 52-60.

10. Sunmola AM (2005) Sexual practices, barriers to condom use and its consistent use among long distance truck drivers in Nigeria. AIDS Care17:208-21.

11. Makanjuola AB, Daramola TA, Obemebe OA (2007b) Psychoactive Substance use among medical students in a Nigerian University. World Psychiatry 48-50.

12. Laosebikan VO, Baiyewu O (2009) Profile of problems associated with psychoactive substance use among long distance commercial automobile drivers in Ibadan. Nigerian Journal of Psychiatry 7: 7-16.

13. Adelekan ML, Makanjuola AB, Ndom RJE, Fayeye JO, Adegoke AA, et al. (2001) 5-Yearly Monitoring of Trends of Substance Use Among Secondary School Students In Ilorin, Nigeria, 1988-1998. West African Journal of Medicine. 20: 28-36.

14. Abiodun OA, Adelekan ML, Ogunremi OO, Oni GA, Obayan AOS (1994) Psychosocial correlates of alcohol, tobacco and cannabis use amongst secondary school students in Ilorin, Nigeria. West African Journal of Medicine13:213-217.

15. Aina OF, Olorunshola DA (2008) Alcohol and substance use portrayals in Nigerian Video Tapes. An analysis of 479 films and implication for public Drug Education. Int QCommun Health Educ28: 63-71.

16. Rasheed KO (2010)the desire to remain awake at night among students of tertiary institution in Lagos state, Nigeria. The health implications. International Journal of Academic Research 2: 29-34.

17. Makanjuola AB, Abiodun OA, Sajo S (2014) Alcohol and psychoactive substance use among medical students of University of Ilorin, Nigeria. European Scientific Journal 10: 69-83.

18. National Population Commission, 2007.

19. Fisher A, Laing J, Stoekel J (1983) Sampling and sample size determination. In: Handbook for family planning operations research design. New York. The Population Council. 31-33.
20. Smart RG, Hughes PH, Johnston LD, Anumonye A, Khant U,et al. (1980) A methodology for student drug use surveys. Geneva: World Health Organization Offset Publication No 50.

21. Adelekan ML, Odejide OA (1989)the reliability and validity of the WHO student drug use questionnaire among Nigerian students. Drug and Alcohol Dependence. 24: 245-249.

22. Adelekan ML, Ndom RJE, Makanjuola AB, Fayeye JO, Adegoke AA, Amusan O (2000) Trend analysis of substance use among undergraduates of university of Ilorin, Nigeria, 1988-1998. African Journal of Drug and Alcohol Studies 1: 39-52.

23. World Health Organization. Traditional Medicine Strategy 2002-2005.

24. Oreagba IA, Oshikoya KA, Amachree M (2011) Herbal medicine use among residents in Lagos Nigeria BMC. Complimentary and Alternate Medicine 117.

25. European Medicines Agency (2008) Committee on Herbal Medicinal Plants (HMPC). Reflection paper on ethanol content in herbal medicinal products and traditional herbal medicinal products used in children. EMEA/HMPC/85114/2008.

26. Yussuman SM, Wilson KM, Klein JD (2006) Herbal products and with substance use in adolescents. J Adolesc Health 38: 395-400.

27. Beccaria Franca, Rolando Sara, AscaniPierluigi (2012) Alcohol consumption and quality of life among young adults: A comparison among three European countries. Substance Use \& Misuse, Early online: $1-10$.

28. Miler W (1998) Researching the spiritual dimension of alcohol and other drug problems. Addiction 93: 979-990.

29. Brown E (2006)the integral place of religion in the lives of rural AfricanAmerican women who use cocaine. Journal of religion and health 45: 19-39.

30. Allen Thomas. Religiosity, spirituality and substance abuse (2009) a thesis submitted in partial fulfillment for the degree of Masters of Science in the Department of Criminal Justice, in the Graduate School of University of Alabama. 